Orbis Tertius, vol. XXIV, nº 30, e124, noviembre 2019-abril 2020. ISSN 1851-7811

Universidad Nacional de La Plata

Facultad de Humanidades y Ciencias de la Educación

Centro de Estudios de Teoría y Crítica Literaria

\title{
De la omnipresencia de la conversación a su ausencia radical y la figura del lector en Cae la noche tropical (1988) de Manuel Puig
}

From the omnipresence of conversation to its radical absence and the figure of the reader in Cae la noche tropical (1988) by Manuel Puig

\section{Ulla Szaszak}

Universidad de Buenos Aires - Universidad de Tres de Febrero, Argentina

ullssz@gmail.com

\section{ReSUMEN:}

En Cae la noche tropical, última novela de Manuel Puig (1988), se despliega nuevamente una cualidad de la voz basada en cierta ética de la inter-subjetividad, en un determinado posicionamiento del lector como, asimismo, en la práctica asidua de la conversación (Link, 2009). Este mecanismo de "presentificación" (Aira, 1990) genera en la novela una imbricación procesual, simbólica, astronómica y existencial, a partir de un vector que marca el trayecto desde la omnipresencia de la conversación entre dos ancianas, Nidia y Luci, hasta su ausencia radical; figura encriptada de la transición vida-muerte que ellas atraviesan, que se replica en el ciclo astronómico de la noche y el día, y revela el momento en el cual el pasaje se hace evidente: el ocaso.

Palabras clave: Inter-subjetividad, Conversación, Voz, Presentificación, Lector.

\section{Abstract:}

Cae la noche tropical, Manuel Puig's last novel (1988), reveals once again a quality of voice based on the ethics of intersubjectivity, a specific location of the reader's figure and, at the same time, a repetitive practice: conversation (Link, 2009). This "presentification" mechanism (Aira, 1990) generates in the novel a symbolic, astronomical and existential imbrication, from an arch that progresses from the omnipresence of conversation to its radical absence, which replicates the process of life turning into death which these two elderly sisters, Luci and Nidia, are undergoing at the same time, and also the astronomic cycle day-night which, on the other hand, reveals the moment in which that passage becomes evident: twilight.

KeYWORDS: Inter-subjectivity, Conversation, Voice, Presentification, Reader.

\section{INTRODUCCIÓN}

En términos generales, este trabajo parte de una de las características que Alberto Giordano (2001) señala como principales en el dispositivo Puig: la narración de voces triviales en conversación, a partir de un dispositivo de escucha y, por tanto, de captura. Si aceptamos que dicho recurso supone una cierta presencia de otro, implícita o explícita, e incluso sin conocimiento expreso del personaje, entonces podríamos proyectar y extender esa figura de "otredad" constitutiva que se revela en relación a los "otros" imbricados en el discurso de un personaje (con mayor o menor conocimiento de ello) hacia una figura exterior, extra-textual y que se posiciona en el "borde": el lector. De este modo, se podría pensar en la inauguración de cierto espacio de inter-subjetividad conceptual que posiciona al lector de Puig en un lugar singular en términos de la instancia de recepción: como un fisgón que escucha tras las puertas sin el beneficio de la posibilidad de ver -siguiendo la metáfora del dispositivo teatral más clásico- a través de la "cuarta pared”. En el teatro, la cuarta pared supone un mecanismo de ilusión por parte de los intérpretes hacia los espectadores de que el espacio físico que éstos últimos ocupan es inexistente o, por el contrario, está de alguna afectado e incorporado dentro del dominio de la ficción. Esto no quita que el público, en ese gesto velado, sea invitado a presenciar la obra. Por el contrario, en Puig la cuarta pared "literaria" es opaca, sólo (o más bien, en principio) accedemos como lectores a cierta "audición" (que no puede ser sino lectura) de voces filtradas. 
En términos particulares, partiendo de esa búsqueda de la singularidad o del efecto de irreductibilidad (Giordano, 2001) en Cae la noche tropical (1988), de Manuel Puig, postulamos que el devenir de la conversación instaura una suerte de arco decreciente que recorre todo el camino desde una omnipresencia de la conversación entre los personajes de Luci y Nidia, -en que se emplean de manera profusa recursos tales como los recomienzos, repeticiones, olvidos-; para luego pasar por lo que llamaremos una presencia limitada, y después por una ausencia relativa, hasta llegar, en el último momento, a la ausencia radical. Este proceso de silenciamiento progresivo tiene su correlato en un momento cronológico de la vida de las protagonistas (la vejez) en que también se cifra el pasaje desde la vida hacia la muerte en una suerte de continuum. Ahora bien, en relación a la función que adopta el acto de conversar, se intentará profundizar en la idea de que en esta novela no se trata de un habla sin fundamento y sin dirección precisa sino más bien de un punto de surgimiento (y de sostén) de un relato: el de Silvia Bernabeu, que sirve de eje estructurante de toda la novela, y que además acusa la presencia de una narradora interna como puesta en abismo (Luci). Esta narración sobre la vecina tiene como objetivo, primero, satisfacer un interés literario de Nidia de escuchar un relato, y de Luci de narrarlo; y luego, disimular el paso del tiempo y la espera de la muerte, a la vez que desviar la atención de sus sucesivas pérdidas de seres queridos. Esta presencia de la muerte se vuelve efectiva para las protagonistas en el momento de la caída de la noche. Es decir, en el "entre" que, en virtud de ese señalamiento del momento de trasmutación, da cuenta de una Stimmung de angustia en las voces de las protagonistas.

\section{LOS OTROS, EL OTRO}

Un primer punto de apoyo para abordar la narrativa de Manuel Puig es el objeto conceptual de "grano de la voz", de Roland Barthes (1986): aquel punto de juntura entre una lengua y una voz, entre lo general y lo singular que hace surgir una especie de fenómeno musical y tonal. ste podría aplicarse no sólo a las voces narrativas expresas y particulares que se plasman en cada novela, sino también a su narrativa en general, como una forma de enunciar en la que se cifra su poder de diferenciación o irreductibilidad (Giordano, 2001). Precisamente, para hacer frente a este último punto, Alberto Giordano se encarga de caracterizar el arte literario de Puig como una "narración de voces triviales en conversación" (2001, p. 4). Sin embargo, la conversación no se concibe sólo en función de cierto género discursivo específico -ese género primario bajtiniano- sino como una disposición básica de las voces en su narrativa que encuentran en sí mismas, de forma explícita o implícita, cierta presencia del otro. Giordano señala:

Cada voz narrada, cualquiera sea el género discursivo en el que se realiza (diálogo, monólogo, cuaderno de pensamientos o carta, diario íntimo o conversación escolar), aparece en conversación. Sin que ellos lo adviertan por lo general, quienes hablan o escriben en las novelas de Puig participan de un vínculo en que otro, un cierto desconocido, obvio o secreto, ya está de algún modo presente (2001, p. 152).

De esta manera, si aquello que Giordano busca localizar, el poder de diferenciación en la literatura de Puig, estuviera en parte en esa orientación ética y ontológica hacia ese otro, entonces lo que se inauguraría es una línea de fuga del texto de sí hacia la diagramación de cierto espacio inter-subjetivo que ésta delimita. Si bien Giordano se refiere al entramado de esos otros dentro del discurso de un personaje -en forma de réplicas imaginarias, de escenas mentales en que éstos intervienen-, tanto de manera ostensible como velada, la singularidad inscripta en los otros en la narrativa de Puig también puede pensarse en el espacio extratextual, en los límites en que el texto se encuentra con un lector, y en los posicionamientos y lugares que el mecanismo de la narración de voces proponen como locus de lectura. En este sentido, la presencia del otro-lector es una figura fantasmática (Link, 2009), entendida como "una figura difícil de asir" (2009, p. 11), evanescente, o bien "una figura que permanece sin interpelar, incluso más allá de la interpelación, no sólo porque la interpelación nunca la alcanza sino porque esta marca el propio límite de la interpelación” (2009, 
p. 11). Es decir, la figura del lector, al estar situada más allá de la interpelación, no puede estar en otro lugar que en la indeterminación y el borde.

Entre los distintos niveles en que se puede rastrear la presencia del otro, hay al menos dos formas en que éste puede intervenir. Una más visible -aunque cabe la posibilidad de que permanezca velada- que es aquella que está en el nivel intra-textual, es decir, hacia el interior de la narración en sí. Éste puede cumplir el rol de un otro-interlocutor efectivo, que recibe el acto de significación en los mismos términos en que es enunciado; que puede ser tanto un otro "externo" o el personaje mismo también en una versión futura. Esto en el caso de una entrada de diario íntimo, en que se contempla el momento de la relectura por parte del mismo personaje pero que ya devino otro. En Cae la noche tropical (1988) se evidencia ese "otro" interlocutor, "textualizado": en principio, la conversación tiene como performers directas a Nidia y a Luci, dos hermanas ancianas, en que la primera está visitando a la segunda en su casa de Río de Janeiro. Es decir que la conversación tiene lugar como una suerte de ping-pong más clásico, en que se señala que la otredad que es constitutiva del género conversación es recíproca, mutable, alternada: una es el "otro" -o la "otra" - de la primera y viceversa.

Ahora bien, otra forma más indirecta de que aparezca el otro, y ese es el caso que analiza Giordano, es la presencia de diálogos imaginarios, con sus réplicas, pero también de alusiones a los que no están presentes bajo cierta forma del entretejido. En el caso de esta novela, se hace evidente que la otra que gira todo el tiempo dentro de la conversación es la vecina, Silvia Bernabeu, en general a partir de un discurso referido e indirecto que Luci trata de reconstruir para Nidia, (aunque también aparezca su voz bajo el formato de cartas). Es decir, Silvia y su vida son un componente temático, pero también son un interlocutor indirecto de un diálogo que establecen las hermanas. Cuando Nidia se refiere a que ella debe ser una mujer de "hacerse programas", de algún modo, entra en un diálogo conceptual con Silvia, y en un intercambio de afectos (negativo) que a pesar de ser unidireccional, no hace indispensable tampoco el conocimiento de Silvia respecto de dichos juicios para que la transacción simbólica ocurra.

La segunda figura de otredad se refiere al plano extra-textual ya que implica un más allá del texto y es más indirecta: el plano de la recepción. Allí se ubica otra de las formas de singularidad en el tipo de dispositivo que Puig construye en su narrativa, que tiene que ver con el posicionamiento del lector como un oyente velado, como fisgón detrás de las puertas o como un lector furtivo de páginas que son ajenas. De modo que, en el plano imaginario, la función del lector tiene un rol activo, casi de actuante, que cumple su rol de husmear las intimidades extrañas desde la invisibilidad. Esto es porque al estar disimulado el lugar del lector a partir de la ausencia de una voz narrativa que organice el relato, por ejemplo; éste, apabullado por un caudal de voces que no sabe a quién pertenecen o de dónde vienen, se abre camino casi como un impertinente. Es justamente el hermetismo de este vínculo de hermanas el que permite intuir esa nueva colocación del lector -ese otro extra-literario-, como aquel que está frente a una cuarta pared que no es una ilusión como en el teatro clásico, sino que es absolutamente palpable en términos de su efecto, ya que a lo que tenemos acceso como lectores es a la audición de esas voces en tanto filtraciones; o de ese cuerpo imaginario. El otro-lector no puede dejar de estar, y en su indeterminación es una certidumbre desclasificada. Lo interesante es que el acto de discurrir presupone cierta exterioridad (no queda en el plano mental) y en ese campo "de afuera" hay un acto de plasmación, y por tanto, ya hay un otro potencial que recibe (discursividades). La contrapartida de ese otro-lector: el narrador, aparece dislocado como lugar de enunciación; de modo que Puig, como señala Delfina Cabrera, "deja de representar la experiencia para aniquilarse como sujeto de la representación" (2016, p. 166), y se alinea con la idea de "salir de sí" de Néstor Perlongher, con la que esta crítica lo relaciona.

Si pensamos, por un lado, en esa escenificación de las voces que realiza la literatura de Puig en relación con la audición de éstas por parte de un lector, podemos señalar que, justamente, durante las conversaciones propiamente mantenidas entre Luci y Nidia, quienes se encuentran compartiendo el departamento en Río, (pero también en las cartas) la vía de acceso que tiene el lector a los marcos de referencia de los personajes, al horizonte temporal, espacial, psíquico que comparten es exclusivamente la materialidad de sus voces transcriptas -o escritas en el caso de las cartas-. En esa idea de "presentificación" (Aira, 1990) (en oposición 
a la de "representación") hay una cierta teatralidad performática, que surge a partir de la ausencia de un narrador que organice el relato (aunque no se puede desoír que en el orden de las voces y la disposición entre conversaciones y cartas hay una intervención narratorial). Esto produce que cualquier figuración visual o simbólica sólo puede ser intuida a partir de lo que se oye (o lee). En ese sentido es que pensamos en la idea de cuarta pared como analogía el dispositivo teatral. En el teatro tradicional ésta genera en el espectador la ilusión de estar "invitado" a presenciar una intimidada partir de las voces y cuerpos en escena. En cierto sentido, hay un "guía" escópico y narrativo que permite seguir el encadenamiento de los hechos. Esto mismo, de forma figurada, podría aplicarse a una literatura que tiene un narrador explícito que ordena los hechos y que guía al lector hacia algún destino.

Sin embargo, en este texto de Puig (y en otros también) la "cuarta pared" en primera instancia es completamente opaca, pero permite figurar ese espacio a partir de la filtración de voces, es decir, una filtración sonora. Salvando las distancias, si la literatura puede tener acceso a un régimen escópico (figurado, imaginario) esto es posible a partir de un narrador que organiza también cuerpos, acciones y objetos en el espacio narrativo; cuando el narrador se retrotrae en la yuxtaposición de voces, entonces todo acceso a la visualidad narrativa imaginaria se hace fragmentaria. Intuimos los cuerpos en el espacio, pero no podemos verlos, sólo podemos oírlos. Este sería el mismo caso de una performance, sólo que a la inversa, en lugar de una visión descontextualizada habrá una audición descontextualizada. Es decir, en la performance se ve el cuerpo en el espacio, que da cuenta de su materialidad y de un proceso transformador, pero se pierde el contexto inmediato, la ligazón de hechos y demás. En la yuxtaposición de voces se privilegia la audición del cuerpo construido; en el cuerpo performático se privilegia la visión del cuerpo material; pero en ambos casos no hay narración (aunque veremos la puesta en abismo en Puig que hace que sí haya una figura narradora).

Un precioso ejemplo performático y de presentificación de la acción está dado cuando Luci, al tener dificultad para dormir, agarra un diario que guardó de antes y leemos (con ella) en tiempo real las notas que le interesan; y después, porque el sueño aún no se produjo, volvemos a leer esas mismas notas con ella pero a partir de una selección fragmentaria que va haciendo; y en ese sentido los efectos del sueño se presentifican en la lectura misma. Hablar y leer aparecen como formas en que se indican formas de ser y estar en el cuerpo. Pero este mecanismo, además pone al lector, nuevamente, en el lugar de un actuante, que va a ser partícipe de la acción del personaje y de hecho va a reproducirla. En ese sentido no sólo hay un "hacer presente" de ese acto de lectura, tanto desde el punto de vista de Luci como desde el lector, sino que también hay un gesto performático, de acción pura que entraña efectos materiales sobre el cuerpo (sueño, cansancio, etc.)

Sin embargo, si el experimento puigiano no llega en esta novela a la radicalidad experimental que estamos describiendo, eso es porque sí tenemos acceso a un régimen narrativo, -y por lo tanto más "visual" que auditivo- ordenador interno del relato que está inserto dentro de él al modo de una mamuschka rusa: hay una narradora interna, en principio, como resultado de una puesta en abismo - un relato dentro del relato-. En un procedimiento típico de Puig, el personaje de Luci toma el rol de relatarle a su hermana Nidia, no películas como en El beso de la mujer araña, o en La traición de Rita Hayworth, por ejemplo, sino toda la chismografía sobre la vida amorosa de su vecina. Este relato sobre Silvia contiene todas las instancias de una narración prototípica: comienzo (cómo se conocen Silvia y Ferreira); punto álgido o clímax (el viaje que ambos hacen a la isla por el congreso de psicólogos y los desplantes de Ferreira) y el desenlace (la desaparición de Ferreira seguida de su reaparición con una nueva pareja). Esto quiere decir que se verifica cierta progresión narrativa y que no se trata del recuento de chismes aislados sino que los hechos tienen un desenvolvimiento temporal. Ahí sí tenemos acceso a cierta reconstrucción imaginaria de los espacios, cuerpos y objetos a partir de la disposición de Luci de narrarlos y de Nidia de escucharlos. Por un lado, entonces, aquella idea de que el "el narrador ha sido asesinado y enterrado en las innumerables capas de subjetividad que constituyen a los sujetos”, tal como enuncia Delfina Cabrera (2016, p. 167) parece ser sólo parcialmente cierta, dado por la efectiva construcción (en esta novela y en otras) de una figura narratorial mediada -y por tanto, indirecta-. El segundo punto que se hace presente con aquella idea de Graciela Goldchuk de que el lector -en este caso- 
de El beso de la mujer araña, "experimenta la ilusión de estar escuchando lo que sucede en un lugar privado al que no ha sido invitado" (2014, p. 12). Esa tensión entre los ámbitos públicos y privados escenificada en la literatura de Puig a partir del posicionamiento del lector, también interviene, como veremos, en el empleo de los discursos que se hace en sus novelas. En Cae la noche tropical, conviven las conversaciones privadas de Nidia y Luci con unos informes policiales: lo público y lo privado, a pesar de estar en tensión, no dejan de presentarse como profundamente imbricados.

\section{DISPOSITIVO DE ESCUCHA Y CONVERSACIÓN}

En resumidas cuentas, si la conversación se orienta hacia un otro, explícito o intuido, entonces se tensiona en el campo de lo intersubjetivo y de la comunicación humana. En ese sentido, resulta importante el procedimiento constructivo que Giordano identifica en la narrativa de Puig:

La literatura de Puig, el universo de representaciones y devenires que llamamos la literatura de Puig, recomienza cada vez con el encuentro, en la escritura, de una voz trivialy una escucha fascinada por las tensiones que la recorren (Giordano, 2001, p. 152).

Ese dispositivo de captura a partir de la escucha, con su componente mecánico: el oído, colabora con la ilusión de que no hay construcción, sino plasmación. Como señala Delfina Cabrera:

El artificio para crear esta sensación, como argumentamos, es el grabador-espía, como todo dispositivo de registro fija lo singular para que luego pueda ser generalizado o, dicho en otros términos, el registro transforma la asistematicidad de la conversación en algo clasificable y discernible llamado "diálogo" (Cabrera, 2016, p. 152) (Los subrayados son propios).

Esa escucha fascinada está menos en la "perfección” de una reproducción de las voces reales, biográficas, determinadas, que en el efecto de "presentificación" que éstas producen, y más que el efecto, en la resonancia que esas voces generan en tanto formas de vida, en su materialidad, en el cuerpo del lector. De modo que Puig escucha para hacer oír a un lector; hay una idea de autor-puente, en realidad, como si éste fuera ajeno a la acción de escribir. Es decir, no se trata del "relato" de algo sino de poner en acción ese algo que se quiere contar: "La presentificación es lumínica, un resplandor para el que se ha creado antes toda oscuridad. Es la creación, en la nada tenebrosa, de un corazón humano cuyo latido se transmuta en visibilidad" (Aira, 1990, p. 3).

En cierto sentido, la singularidad de Puig estaría en parte en su cualidad camaleónica de hacer emerger singularidades sonoras: voces particulares. Así es que la escucha de las "tensiones" que las recorren tiene que ver con la atención al "grano de la voz", en términos de Roland Barthes. Se trata de "una doble postura" o "doble producción”: la voz como lengua y también como música; es decir, como una cualidad. De lo que se trata es de ver en ese cuerpo viviente la singularidad de los modos de articular: "la materialidad del cuerpo hablando su lengua materna" (Barthes, 1986, p. 265). Precisamente, Puig "no asume ni una voz ni tampoco sus silencios" sino que "presenta voces en su registro, siempre mediadas, ya sea por una escucha, por unas notas, por una correspondencia interceptada o por un grabador-espía" (Cabrera, 2016, p. 164).

Ahora bien, respecto de la diferencia entre diálogo y conversación, Daniel Link señala:

Lo que diferencia al diálogo de la conversación en literatura es del orden económico: en el primer caso personajes significativos en relación con el relato pronuncian enunciados significativos respecto de su desarrollo (Hemingway, Chandler). La conversación y Puig es el primero (o el segundo) en notarlo, es una deriva temática y discursiva: el habla sin fundamento y sin destino preciso: la vida misma (Link, 1994, p. 53).

Esta diferencia en la economía de la conversación -orientada hacia una especie de derroche improductivofunciona en esta novela, en algún sentido, de manera doble y paradójica. Hay por un lado cierta exuberancia discursiva: una proliferación de múltiples zonas conversacionales -muchas veces simultáneas-, con repeticiones, recomienzos, olvidos, malentendidos, en fin, todas las "imperfecciones" de las formas de continuidad del habla. Se trataría de una falta de economía en las formas. Sin embargo, toda aquella profusión 
de discurso desemboca no tanto en una "deriva temática y discursiva" y un "habla sin fundamento y sin destino" en esta novela en particular. Si bien es cierto que hay alguna dispersión temática, en realidad toda la conversación gravita en torno a la narración lineal y continúa de la vida de la vecina. Este relato conversado y progresivo tiene una especie de objetivo difuso; si en Cae la noche tropical lo que parece narrarse es la pérdida de ese otro -y el augurio de la pérdida de uno mismo- a manos de la vejez, se habla para asegurarse de que el otro sigue allí, para rodear, disimular un presente de pérdidas, para acelerar el paso del tiempo y para olvidar. Es decir, se narra para intentar evadir -muchas veces infructuosamente- la realidad, como una ilusión compensatoria del tiempo; instaurar un tiempo otro, en el cual los protagonistas son otros y uno puede simplemente sentarse a imaginar otras vidas. No sólo parece manifestarse como un mecanismo de "escape": el pedido de detalles mínimos, etc., sino también como una forma de hacer pasar el tiempo, es decir, hacer pasar el tiempo hasta que "caiga la noche", el cuerpo se canse, y ambas protagonistas "consigan dormir". De lo que se trata es de disimular la espera de la muerte. Hablar es una forma de evasión y de ventilar las angustias. También implica un distanciamiento afectivo; Nidia mantiene casi hasta el final de la novela una postura de jueza crítica de las acciones "de programas" de la vecina de Luci; es decir, en un desapego que le permite evitar la identificación y por tanto, descubrir las resonancias de esa vida en la suya propia.

\section{DE LA OMNIPRESENCIA DE LA CONVERSACIÓN A SU AUSENCIA RADICAL}

Podríamos decir, entonces, que parece haber un vector en Cae la noche tropical, un especie de progresión narrativa que recorre todo el arco desde la omnipresencia de la conversación hacia su ausencia radical, pasando en el medio por lo que podríamos llamar una presencia limitada y luego por una ausencia relativa. Llamamos omnipresencia de la conversación a la posibilidad de la continuidad de las voces de las protagonistas en el espacio intersubjetivo "a toda hora" y de forma inmediata. En el discurrir de la primera parte de la novela la conversación entre las hermanas Nidia y Luci, el hecho de que compartan un mismo espacio corporal y sonoro -el departamento de Luci en Río de Janeiro-, se habilita la característica de una fluidez casi ininterrumpida de intercambios conversacionales, es decir, se recurre a aquella exuberancia, abundancia y reflujo del habla propia del género. Lo que se pone de manifiesto, entonces, es el fenómeno de la recursividad de las voces. Hay ciertos patrones de repetición de información ya dicha, en que se retoma lo anterior y se lo proyecta al porvenir. No es posible pensar en conversaciones del todo lineales, ya que en medio de la narración de una escena surgen dispersiones temáticas, y por eso se debe volver a decir algo para religar lo anterior, especialmente cuando Nidia quiere que Luci retome la narración sobre la vida de "la de al lado". La deriva discursiva, a diferencia de lo que constituiría un diálogo puntual y "económico" y significativo, tendría más que ver con la plasmación de un carácter vital, desordenado, imperfecto de la conversación que está sujeta a olvidos, fallas en la audición, lagunas de memoria, repeticiones periódicas que no siguen lógicas causales o predecibles sino más bien asociativas: "la vida misma".

Sin embargo, como hemos visto, esa presentificación de la conversación no se agota en esa especie de "derroche improductivo" per se, sino que está en función del relato acerca de Silvia, que sirve como eje estructurador en torno al cual todas las reformulaciones y recomienzos se organizan. Ese mecanismo de "reflujo" parece importante para mantener la ligazón del relato que en un primer momento le cuenta Luci a Nidia; es decir, para evitar pérdidas involuntarias de información. Como la charla se ramifica en muchos focos y nunca en uno solo, ésta se esparce, hay un descentramiento. Es una poética, entonces, que por fundarse en la repetición, constituye un exceso. Aún con interrupciones y cambios de foco, siempre se termina volviendo al relato principal. Por ejemplo, Nidia pregunta: “-¿Ella por qué se vino a Río?” y Luci le responde:

"-Se fue de la Argentina en la época de Isabelita y la triple A." (Puig, 1988, p. 8). Ahora bien, unos fragmentos de conversación más adelante“-Contame de la de al lado, ¿por qué se fue de la Argentina? -Ya te dije, por amenazas de las tres A ¿Te acordás? la triple A” (Puig, 1988, p. 9). No parece menor que se refuerce uno de los únicos datos referentes al contexto político argentino de los años '70; la atención que Puig presta 
a éste tendría que ver con aquello que Giordano señala como quiebre a partir de El beso de la mujer araña: cierto desplazamiento de sus intereses políticos y un guiño hacia un relativo presente -Se refiere a la década del '70 y la novela se publica en la del ' $80-$, en contraposición a sus novelas anteriores, en que predominaba una rememoración más bien nostálgica, según Giordano (2001). Otro ejemplo de reiteración es: "La madre mira la televisión y a las diez de la noche ya se le cierran los ojos, de tanto ver televisión todo el día. Él le pide que se levante más tarde, así a la noche no tiene tanto sueño y pueden conversar un poco." (Puig, 1988, p. 17). Y tres páginas después Luci retoma: "la cuestión es que este hombre llega a la casa a la noche rendido de cansado. Y está la madre viendo algo por televisión" (1988, p. 20).

Dicho mecanismo de la repetición es una característica inscripta en las voces de Nidia y Luci, para las cuales las lagunas de memoria son recurrentes; es decir, la construcción del rasgo que ambas comparten: su adscripción a la tercera edad.

Por otra parte, hay un rasgo que persiste en todo el arco de la conversación, de principio a fin, que tiene que ver con una escucha literaria por parte de Nidia, que es la oyente. El relato literario -que al interior de éste se presenta como no ficcional, o verídico- toma la forma de la narración oral, pero además tiene la particularidad que se va construyendo en tándem, de a dos: la escucha de Nidia no es pasiva sino que interviene reorientando la narración. Por un lado, Nidia agrega capas de interpretación al relato, lo cual lo amplifica con nuevos matices: es decir, emite juicios de valor respecto de Silvia. Por ejemplo, la acusa de "ser de programas" y de agenciarse varios hombres como puede. Pero además de esta lógica aditiva, también interviene en el decurso de la narración a partir del reclamo de algunos detalles o de que se detenga más en alguna cuestión (y no en otra); es decir, una suerte de ampliación selectiva guiada por los intereses de la oyente. "-Quedaste en explicarme lo de la voz del hombre, qué era eso que la impresionaba tanto" (Puig, 1988, p. 33). Lo mismo con el pedido de la descripción de los ojos de Ferreira y de los "detalles picantes". También aparece la idea de la audición literaria como un viaje: "-Contame, Luci, yo cierro los ojos y hago de cuenta que estoy viajando. Empezá de nuevo” (Puig, 1988, p. 61).

Un segundo momento de la progresión lo conforma aquello que podríamos llamar una presencia limitada, que está dada por el viaje que hace Luci a Lucerna, Suiza, para reunirse con su hijo, quien espera verla establecerse allí. Es decir que la conversación entre ambas ancianas continúa pero la posibilidad de fluidez está, en alguna medida, obturada. Esto es porque toma la forma de la correspondencia y por lo tanto está mediada tanto por el espacio: Nidia está en Río de Janeiro y Luci en Lucerna, como por el tiempo: el momento de escritura de una carta no coincide con su momento de recepción. Es decir que ya hay una progresión hacia una forma de la conversación discontinua: en la lectura de cartas y escritura de respuestas hay espera; no hay posibilidad de flujo, de frecuencia, de inmediatez como sí hay en la conversación in situ. Estas características espaciales y temporales también introducen una lógica más ecónoma en la conversación, no sólo respecto del caudal o el quantum de la conversación, más limitado, sino también porque se reducen los fenómenos de los recomienzos, las repeticiones, los olvidos, etc., que sí permean más la conversación que comparte un mismo espacio témporo-espacial. De hecho, esas condiciones de posibilidad para la conversación están tematizadas. Luci escribe: "Si me hiciste caso y me escribiste a los tres días de mi salida ya mañana podría llegar tu carta. Espero que no te haya dado pereza escribir" (Puig, 1988, p. 92).En otro pasaje "Querida Luci: Hoy al mediodía llegó tu carta, no alcanzo a ir al correo esta tarde misma porque te acordarás que a las cinco las retiran y ya son las cuatro" (Puig, 1988, p. 96). En estos fragmentos se visibiliza la discontinuidad pero en dos sentidos diferentes; por una parte en el segundo fragmento se manifiesta aquella que está basada en la distancia temporal (y espacial) - por lo que la continuación está sujeta a algo así como una suspensión en el intercambio- . Y en el primer fragmento se observa la discontinuidad de la conversación en el sentido de una linealidad que se quiebra. Si Nidia escribe una carta a tres días de la partida de Luci, (y por lo tanto sin recibir la carta de ésta) se inaugura la posibilidad de que se produzca una conversación bifurcada: no estructurada por preguntas y respuestas; es decir, en una sucesión lógica en que las cartas se encadenan en 
virtud de ser contestaciones o comentarios respectos de una carta anterior. En ese caso, la conversación adopta cierto carácter errático, de mosaico que toma su sentido en una yuxtaposición.

En un tercer momento aparece lo que se podría llamar una ausencia relativa. Por una parte, la ausencia se encripta en la muerte de Luci, es decir que al perder Nidia a su interlocutora, a su "otra", se obtura la posibilidad del diálogo y se vuelve unilateral, por ende, un monólogo. Sin embargo, la relatividad de esa ausencia está dada porque la conversación entre Nidia y Luci "continúa" en términos simbólicos, es decir, no de forma efectiva y concreta sino a partir de una figura -fantasmática, por otra parte- que actúa como receptora en lugar de ese referente perdido: Luci. Como ninguno de los familiares quiere informarle la muerte de su hermana a Nidia hasta que ella vuelva a Buenos Aires, ella permanece ajena a lo sucedido, de modo que sigue enviando sus cartas y la cadena de conversación persiste, pero en otros términos: éstas encuentran un destino dislocado, su sobrino el Nato (el hijo de su hermana) que es quien las contesta. Él, como figura vicaria, nunca logra erigirse en interlocutor de Nidia, porque ella nunca lo toma como tal; es decir que él sólo aparece en sus cartas sólo como una tercera persona aludida y nunca como alocutario. Nidia sigue dirigiéndose de forma directa a su hermana muerta, si bien es el Ñato el que le responde alegando que Luci está recluida en su habitación por problemas de salud: ficción que su sobrino inventa para no generar perturbaciones en Nidia. "Mamá sigue indispuesta y debe guardar cama" (Puig, 1988, p. 103). Es decir que en el caso del Nato no se trata simplemente de borrar las marcas del cuerpo que ya no está; es decir, emplear la elipsis sino que incluso se proyecta la figura de Luci de modo fantasmático sobre el espacio material: una habitación en la casa de Lucerna, pero también un espacio simbólico de imposibilidad de escritura. También en este segmento se puede agregar toda la correspondencia que rodea literalmente a Nidia en torno a la muerte de su hermana, entre Silvia Bernabeu y Alfredo Manzarino -el Nato-, como un modo de urdir y asegurarse un silencio y continuar el simulacro.

El último estadio del proceso de silenciamiento está dado por la ausencia radical, que tiene que ver con el reconocimiento de la inhabilitación de ese espacio intersubjetivo y de flujo de voces por parte de Nidia de su diálogo con Luci, que refiere al silencio final. Este momento de reconocimiento está elidido. Lo que allí se evidencia es el apagamiento de la vida: la muerte. Pero también aparecen en este último tramo los informes policiales, documentos para ser leídos por la burocracia interna o judicial también, sobre el caso de la desaparición de la niñera que vive con Nidia, María José Oliveira da Cuhna, embarazada de Ronaldo. Este tipo de documento cambia abruptamente los regímenes de la comunicación: del ámbito íntimo o privado se pasa a un tipo de comunicación al menos semi-pública e impersonal, y en ese sentido inhumana, porque es aquel dispositivo que sigue funcionando independientemente de la vida de la persona a la cual se refiere y que tiene la capacidad de preservarse y trascender (sobrevivir) frente al ciclo vital de una persona. Y además es aquel tipo de discurso que precisamente trasmuta lo privado en público, que arranca información del seno de las vidas particulares y la expone a partir del régimen punitivo.

En cierto sentido, el recorrido por este arco que va desde una omnipresencia hasta la ausencia final de conversación trabaja textualmente la transición vida-muerte en esta novela, la díada conversación y ausencia de conversación, no como un corte tajante sino como algo sujeto a una suerte de gradualidad para completarse. Esto replica el proceso de "ocaso" de la vida como una progresión paulatina que desemboca en la muerte. En este sentido, el movimiento narrativo y metafórico por el que opta Puig es justamente replicar esa lógica progresiva de la vida humana que culmina en la muerte con otro ciclo natural, que es el astronómico, y que incluye al humano, pero lo excede. Es decir, aquellos movimientos de rotación planetaria que hacen que lo que llamamos "el día" pueda transfigurarse en "noche". La diferencia entre el ciclo astronómico y el ciclo humano es justamente la posibilidad de repetición del primero; por eso los polos vida y muerte aparecen también encriptados en esa escala menor que sería la del sueño-vigilia, según las funciones humanas que éste marca (y que progresivamente dibujan el arco entre vida-muerte) y, en términos de la novela, entre conversación y silencio. Si durante del día se conversa, de noche la conversación cesa. Es decir que los movimientos planetarios son aquellos que por un lado, exceden lo humano, y por el otro se fundan la 
repetición; pero que a la vez le sirve de espejo a mínima escala de la vida humana en el transcurso de un día, es decir, en un plano micro.

De este modo, el proceso narrativo que se traza entre la omnipresencia de la conversación hasta su ausencia radical, o entre vida y muerte, se halla puesto en evidencia como herida cuando las protagonistas se hacen conscientes de la transformación: se trata de la revelación que emerge durante el ocaso, el momento de la caída del sol que anuncia una noche que todavía no llegó, es decir, que señala el "entre". Si es el momento en que se reconoce dicho pasaje, también constituye la metáfora del acercamiento de la muerte de dos ancianas. Por una parte, si entendemos la Stimmung como una tonalidad emotiva o disposición afectiva, y en términos de Heidegger como "un modo existencial fundamental" a través del cual el dasein se abre a sí mismo (al mundo); o a partir de Agamben (2005) quien la aproxima a la Stimme (voz en alemán) que pertenece a la esfera acústico-musical; se puede pensar que aquello que se hace presente en las voces de las protagonistas durante ese "entre" es la angustia por la muerte, no sólo la propia sino la de los seres queridos que ya no están:

-Qué tristeza que da a esta hora ¿por qué será?/ -Es esa melancolía de la tarde que va oscureciendo, Nidia. Lo mejor es ponerse a hacer algo, y estar muy ocupada a esta hora. Ya después a la noche es otra cosa, se va esa sensación./ -Sobre todo si se puede dormir bien. Y así no se piensa en las cosas terribles que ocurrieron (Puig, 1988, p. 4).

Ahí se pone en evidencia la noción de la pérdida y también la necesidad de una ocupación, una distracción que desvíe la atención hacia otra cosa: el relato, la historia de Silvia, etc. De modo que el objetivo de la conversación es eludir la realidad y refugiarse en el relato si bien ésta no deja de colarse por los intersticios. Me refiero a las sucesivas pérdidas afectivas, en especial, la muerte de la hija de Nidia, Emilsen.

Por otra parte, en la idea de "caída" habría algo de la idea de lo irremediable, y en esa organización "arriba/ abajo" también cierta idea de la teología cristiana de aquello que "cayó" en pecado, como aquello que no pudo mantener la "gracia" para quedarse en el paraíso. En ese mismo campo semántico entra esa frase recurrente tanto en Nidia como en Luci: -Nidia, hay gente que tiene más suerte ¿o es que nadie se la lleva de arriba?" (Puig, 1988, p. 24). En esa valoración de lo que pertenece al ámbito "de arriba" es agradable, placentero, afortunado, en oposición todo lo que se oponga a "arriba" va a ser "abajo"; y esa imposibilidad de salir indemnes se juega la fatiga de la vejez en estos dos personajes, y el sufrimiento asociado a la vida -en especial en relación con la muerte-.

El tono en la voz de Nidia es de impugnación paradójica, por un lado hay un cierto juicio hacia la forma que tiene Silvia de llevar adelante sus amores; pero sin embargo ese ánimo que se resiste ante esa subjetividad otra, que tiene determinada aversión, también demanda saber cómo continúa la historia, y exige ciertos detalles, por ejemplo "lo picante" que Luci parece prometerle pero que nunca llega a tiempo. Y el trópico opera su influjo (contario al que pensaban los médicos, quienes reparaban en el efecto nocivo que podría tener el clima de Río de Janeiro sobre la salud de la paciente); ese tono defensivo cede y se trasforma en un tono compasivo, en el cual se conduele de la realidad de un portero nordestino y de su esposa, que trabaja como sirvienta. Es decir que el trópico, en una lectura algo determinista, ablanda el grado de resistencia del personaje para entrar en contacto con los otros. En un caso, estaba inhabilitada para empatizar con una psicóloga, mujer que concibe como buscona; pero sí empatiza con un hombre de posición económica difícil, y su mujer, que no conoce, pero que piensa que debe ser "más buena que el pan".

\section{ConClusión}

Para finalizar, en términos generales podemos señalar que en la narrativa de Puig una de las marcas de singularidad de la voz, en tanto conjunción entre lengua y música: Stimme, está dada, a partir de un cierto posicionamiento del lector, quien aparece como una figura actuante y entrometida en las intimidades de los demás, en tanto está frente a una "cuarta pared" opaca, en términos del dispositivo teatral; a la vez que la puesta en texto de voces triviales conversando implica cierta dimensión de la performance, en el sentido de 
que sólo se ocupa de la materialidad de lo que ocurre y de aquello que es contrario a la idea de representación cuestión que Aira retoma a partir de la idea de presentificación-. Y en términos específicos, podemos señalar que en Cae la noche tropical el decurso de las voces en conversación sufre un arco de descenso desde una omnipresencia de la conversación hasta su ausencia radical; que se entronca con las variables humanas de la vida que progresa hacia la muerte (y de la pérdida del otro). A su vez, se halla inscripto en otro ciclo, que es el astronómico: el día que se transmuta en noche. De modo que la conversación, más que del lado de la exuberancia del habla, del exceso, de la abundancia, está orientado hacia disimular la espera de la muerte y el de los seres queridos, pero además, propiciar un relato y un tipo de escucha literarios.

\section{REFERENCIAS}

Aira, C. (1990). El sultán. América Hispánica, 4, pp. 9-12.

Agamben, G. (2005). Vocación y voz y El yo, el ojo, la voz. En La potencia del pensamiento. Buenos Aires, Argentina: Adriana Hidalgo.

Amícola, J. (2000). Manuel Puig y la narración infinita. En Elsa Drucaroff(dir.) La narración gana la partida, Historia de la literatura argentina, tomo 11. Buenos Aires, Argentina: Emecé.

Barthes, R. (1986). El acto de escuchar, El 'grano' de la voz, y La música, la voz, la lengua. En Lo obvio y lo obtuso. Medrano. Barcelona, España: Paidós Comunicación.

Cabrera, D. (2016). Las lenguas vivas. Zonas de exilio y traducción en Manuel Puig. Buenos Aires, Argentina: Prometeo.

Giordano, A. (2001). Manuel Puig. La conversación infinita. Rosario,Argentina: Beatriz Viterbo.

Goldchuk, G. (2014). El brillo de una vinchita de nylon. En Carina González (ed.). Fuera del canon: Escrituras excéntricas de América Latina. [S.I.]. Pittsburgh, Estados Unidos: Universidad de Pittsburgh.

Link, D. (1994). El boom, Manuel Puig, la realidad: aspectos de una teoría de la representación. En La chancha con cadenas. Buenos Aires, Argentina: Ediciones del Eclipse.

Link, D. (2009). Umbral y Cartas. En Fantasmas. Imaginación y sociedad. Buenos Aires, Argentina: Eterna Cadencia.

Puig, M. (1988). Cae la noche tropical. Barcelona, España: Seix Barral. 